\title{
Pricing Monitoring Uncertainty in Climate Policy
}

\section{Environmental and Resource Economics 68 (4), pp.949-974}

\begin{abstract}
This article assesses the environmental and economic efficiency of three different approaches to treat monitoring uncertainty in climate policy, namely prescribing uncertainty, setting minimum certainty thresholds and pricing uncertainty through a discount. Our model of the behavior of profit-maximizing agents demonstrates that under the simplest set of assumptions the regulator has no interest in reducing monitoring uncertainty. However, in the presence of information asymmetry, monitoring uncertainty may hamper the economic and environmental performance of climate policy due to adverse selection. In a mandatory policy, prescribing a reasonable level of uncertainty is preferable if the regulator has enough information to determine this level. For voluntary mechanisms, such as carbon offsets, allowing agents to set their own monitoring uncertainty below a maximum threshold or discounting carbon revenues in proportion to monitoring uncertainty helps the regulator mitigate the negative effects of information asymmetry. These conclusions are much more pronounced when agents do not accrue revenues from their mitigation action, other than carbon. Our analysis of monitoring uncertainty under information asymmetry, which results in heterogeneity in the agents' benefits from abatement, generalizes the classical trade-off between production efficiency and information rents.
\end{abstract}

Authors: Valentin Bellassen*1, Igor Shishlov*2,3

* Both authors equally contributed to this article.

1 CESAER, AgroSup Dijon, INRA, Univ. Bourgogne Franche-Comté, F-21000 Dijon, France

2 I4CE - Institute for Climate Economics, 75009 Paris, France

3 CIRED, CIRAD, 94736 Nogent-sur-Marne, France

\section{Detailed contact information:}

Corresponding author: 
Dr. Valentin Bellassen

INRA researcher

UMR CESAER (1041)

26 bd Docteur Petitjean, BP 87999, 21079 Dijon Cedex, France

E-mail: valentin.bellassen@dijon.inra.fr

Co-author:

Dr. Igor Shishlov

Project Manager, I4CE - Institute for Climate Economics

47 rue de la Victoire, 75009 Paris, France

Researcher, CIRED (Centre International de Recherche sur l'Environnement et le Développement)

45 bis, avenue de la Belle Gabrielle, 94736 Nogent-sur-Marne, France,

E-mail: igor.shishlov@i4ce.org

\section{Acknowledgements:}

The authors would like to thank Stephane De Cara (INRA), David Driesen (Syracuse University College of Law), Franck Lecocq (CIRED), Juan-Pablo Montero (Economics Institute of the Pontificia Universidad Católica de Chile), Romain Morel (CDC Climat Research), Marie-Laure Breuillé (INRA) and Sophie Legras (INRA) for their valuable inputs.

This work benefited from external funding from Agence Française de Développement; EIT Climate-KIC; Ministère français de l'Agriculture, de l'Agroalimentaire et de la Forêt; Ministère français de l'Ecologie, du Développement Durable et de l'Energie; and Union des Industries de la Fertilisation. 


\section{Introduction}

Implementing climate policies - be they carbon pricing mechanisms or direct regulations - requires monitoring the level of emissions or abatement of the agents that receive an incentive or a penalty. For example, on a jurisdictional level, national greenhouse gas (GHG) inventories reported under the UNFCCC provide the basis for assessment of compliance of the parties to the Kyoto Protocol. On a private entity level, annual monitoring of GHG emissions under the EU Emissions Trading System (EU ETS) serves to determine whether a company has a deficit or a surplus of emissions allowances. Finally, on an offset project level, quantification of emissions reductions defines the amount of carbon credits that a project is entitled to receive. Similarly, in non-pricing policies monitoring GHG emissions may be necessary to determine whether an agent complies with an emissions standard or whether he is entitled to receive a public subsidy.

Monitoring GHG emissions in climate policies is usually the responsibility of an agent - be it an offset project developer, a company subject to an ETS or a party to the Kyoto Protocol - who also bears the costs of monitoring (Bellassen and Stephan 2015). The implementation of monitoring rules prescribed by the regulator comes with an uncertainty range: the exact amount of GHG emissions differs from the amount reported by an agent (Bellassen et al. 2015). Agents may or may not be aware of this difference, which effectively results in the presence or absence of information asymmetry between an agent and the regulator.

Currently, existing carbon pricing policies deal with monitoring uncertainty in three - often exclusive ways: prescribing the level of uncertainty, setting maximum tolerated uncertainty thresholds, and implicitly or explicitly discounting the abatement incentive in proportion to the uncertainty level (Bellassen et al. 2015). There is no consensus regarding the efficiency of different approaches to address this issue in climate policy - for example in the Clean Development Mechanism (CDM) monitoring uncertainty is not treated in a consistent manner across different sectors and methodologies (Shishlov and Bellassen 2015). The main objective of this article is therefore to compare the efficiency and distributional effects of different approaches to treat monitoring uncertainty in climate policy. To this end, we develop a microeconomic model of behavior of profit-maximizing agents taking into account monitoring costs, uncertainty of GHG emissions abatement and different scenarios regarding information asymmetry.

The rest of the article is organized as follows. Section 2 briefly reviews the existing literature on monitoring uncertainty and information asymmetry in environmental economics. Section 3 presents the model and 
different information scenarios. Section 4 solves the model analytically - where feasible - and provides a numerical application for two cases of GHG emissions abatement: improved energy efficiency and landfill gas flaring. Section 5 synthesizes the results and discusses the key trade-offs for the regulator. Section 6 concludes the analysis with some policy recommendations and considerations for future research.

\section{Literature review}

Uncertainty has been subject to research in environmental economics since the seminal work of Weitzman (1974), which investigated the merits of price and quantity regulations when the regulator has imperfect information on the aggregate abatement cost curve. In an ideal mathematical world both cap-and-trade and Pigouvian taxation instruments manage to perfectly internalize the cost of pollution and restore the first-best solution in terms of social welfare. However, when abatement costs and benefits are uncertain, the results may differ. Indeed, if the pollution damage curve is much steeper than the abatement cost curve - such as for example in the case of runaway climate change - setting a price and letting the market decide on quantity may be too risky. Conversely, if the social cost of pollution is rising gradually compared to abatement costs around the optimal quantity of pollution, setting a cap may result in unsustainable costs for society.

Along these lines, several studies have proposed to adjust the instrument when the level of pollution of individual firms is not perfectly known. Most often, this adjustment consists of a revised level of the Pigouvian tax, different from the seminal level which equates marginal costs and benefits of abatement. We identified two lines of relevant literature: one is concerned with restoring the optimal level of social welfare without budget constraint for the regulator and therefore pays no attention to welfare transfers between agents. The other assigns a budget constraint to the regulator and is therefore mostly concerned with information rents, i.e. unnecessary transfers from the regulator to efficient agents mimicking inefficient ones.

Adding monitoring error into the seminal framework of Becker for crime penalties (Becker 1968), Png (1986) finds that penalties for convicted criminals should be increased and that the overchilling effect of this increase needs to be compensated for by subsidizing everyone. Chakraborty and McAfee (2014) translates this question to continuous setups such as car speeding and finds that the penalty needs to be adjusted by $-\frac{s^{\prime \prime}(x) \times \sigma(x)}{2}$ where $\mathrm{x}$ is the magnitude of the offence (i.e. speed), $\mathrm{s}^{\prime \prime}(\mathrm{x})$ is the second derivative of the damage function (i.e. probability of injuring a bystander) and $\sigma(x)$ is the monitoring uncertainty (i.e. the measurement error of a speed camera). A useful corollary of this proposition is that the monitoring 
uncertainty does not require the adjustment of the penalty when the damage function is linear $\left(s^{\prime \prime}(x)=0\right)$. These two papers take a single agent perspective and therefore neglect the possibility of asymmetrical information, and therefore of adverse selection.

In the field of environmental economics, Dasgupta et al. (1980) consider agents with heterogeneous abatement costs and propose a general form for a tax scheme that maximizes welfare both with and without information asymmetry between regulator and agents. However, as Chakraborty and McAfee (2014) put it, "existence theorems are often cold comfort to someone who needs to use a construct". Segerson (1988) considers agents with heterogeneous abatement costs and offers a solution in the case where only the total level of pollution is observed and not the individual pollution discharge of each firm. But her solution requires several strong assumptions and most remarkably the knowledge of the conjecture functions of all firms, that is what each firm expects other firms will do under a given incentive level.

Montero (2005) also assumes abatement costs heterogeneity and studies the case where individual pollution rates - i.e. $\mathrm{tCO}_{2}$ e per ton of output - are known, but not individual emission levels - i.e. $\mathrm{tCO}_{2} \mathrm{e}$ per firm. In this context, a policy of tradable permits does not always improve social welfare over fixed emissions standards, especially when the abatement cost heterogeneity among agents is low. This informational setup may be a good approximation of the monitoring rules prevailing in Santiago-Chile's scheme to reduce total suspended particulate emissions, but it does not fit climate policies. In climate policies, inputs and outputs - activity data - are indeed usually monitored, and the associated uncertainty is usually lower than the uncertainty of pollution rates - emission factors (Bellassen and Stephan 2015). Because these frameworks neglect the possibility of adverse selection or assume informational setups that do not match the current practice in climate policies, they were not suited to our aim of assessing the efficiency and distributional effects of different approaches to treat monitoring uncertainty in climate policy.

In the absence of budget constraint, the potential inefficiencies stem from the over/under-abatement by agents with high/low abatement costs as the incentive cannot be tailored to the individual emission level. When a budget constraint is imposed to the regulator - which usually limits the total amount of subsidies distributed but can be generalized to a maximum taxation revenue or abatement level, the potential inefficiencies come from information rents, that is useless transfers from the regulator when he does not know with certainty the abatement cost functions of all agents. 
The second line of literature studies this context, where the regulator has only uncertain information on agents' costs - typically the range - while agents themselves have perfect information on their costs. This setup has been extensively studied in the field of procurement and regulation (Laffont and Tirole 1993). Canton et al. (2009) adapts this literature to the context of environmental economics and in particular spatial heterogeneity in abatement costs. It finds that spatially disaggregated information allows the regulator to improve the efficiency of environmental subsidies. Yet, it disregards that more precise information may be costly to obtain.

In the specific context of soil carbon sequestration, Antle et al. (2003) consider this trade-off between improved efficiency of environmental scheme and cost of information, assessing the worth of monitoring soil carbon at the finer agro-ecozone scale rather than the default regional scale. While we are interested in the same trade-off, the binary form of information is somewhat limiting and, more importantly, the regulator is assumed to monitor environmental benefits whereas in actual climate policies agents are in charge of monitoring and the regulator simply verifies that this monitoring is performed in accordance with the rules (Bellassen and Stephan 2015). In the field of climate policy, Montero (2000) considers asymmetrical information in the case of voluntary opt-in programs. It demonstrates that asymmetrical information results in a tradeoff between efficiency gains due to involvement of low-cost emissions reductions and excess emissions due to the adverse selection of firms that produce a level of emissions below the permit allocation.

van Benthem and Kerr (2013) and Bento et al. (2015) build upon Montero (2000) to assess different policies in the context carbon offsetting schemes, namely increase in baseline scale, offset discounting, stringent baselines and offsets limit. Interestingly, they broaden performance criteria by tracking distributional transfers in addition to economic efficiency. They find that when limiting transfers is part of the objective, setting baselines, in particular large-scale ones, is the best instrument. Like them, we find that there is often a trade-off between efficiency and transfers. Unlike them however, we focus on the policy options related to the level of monitoring uncertainty and the associated monitoring costs.

The existing literature thus provides important insights into the potential sources of inefficiency and the choice of policy under different types of uncertainty and information asymmetry. Yet, the existing literature is mostly based on a theoretical approach, taking into account neither the existing monitoring rules in climate policies nor empirical data. Moreover, when information asymmetry occurs, most papers - with the exception of Antle et al. (2003) - assume that this asymmetry occurs on the costs of using an abatement technology rather than the level of abatement obtained by the implementation of the 
technology. As a result, none of the aforementioned models are fit to assess the impact of existing monitoring rules on social welfare. This article attempts to bridge these gaps by incorporating existing monitoring approaches into a simple model and by providing numerical simulations based on the empirical data.

The policy relevance of the topic can be highlighted by the ongoing discussion regarding the monitoring, reporting and verification (MRV) provisions - also known as 'transparency' - under the Paris Climate Agreement (Bultheel et al. 2015) and the current reform of the CDM regarding inter alia the monitoring uncertainty rules (Shishlov and Bellassen 2015). The latest scandal with Volkswagen that equipped its diesel cars with special software to tweak their emissions tests (The Economist 2015) and the reports regarding the increased methane emissions in the US that are not reflected in the national inventory (Turner et al. 2016) further demonstrate the timeliness and importance of this topic.

\section{Description of the model}

In order to compare the efficiency and distributional effects of different approaches to address monitoring uncertainty in climate policy, we develop a simple microeconomic model of behavior of profit-maximizing agents. The model takes into account the uncertainty associated with monitoring GHG emissions or emissions reductions, monitoring costs and information asymmetry.

\subsection{Assumptions}

In both mandatory and voluntary carbon pricing mechanisms agents 'produce' GHG emissions reductions - abatement - in order to obtain economic benefits. These benefits may come in the form of reduced amount of emission permits they have to purchase within an ETS, reduced amount of carbon tax to be paid, or tradable credits generated in a carbon offset project. Although we use data from a carbon offset scheme for the numerical applications, the model developed in this article applies to all the aforementioned carbon pricing mechanisms, with either voluntary or mandatory participation. The difference between the latter two options is materialized by the profitability constraint, which appears in the case of a voluntary scheme, whereas it is absent from a mandatory scheme as long as carbon represents a small fraction of firms turnover.

Carbon price $\boldsymbol{p}$ is assumed to be exogenous - that is, agents cannot influence the level of carbon tax or the market price of carbon in an ETS - and is equal to the social cost of carbon. An agent $\boldsymbol{i}$ produces GHG abatement $\boldsymbol{q}_{\boldsymbol{i}} \geq \mathbf{0}$. Carbon pricing policy is then applied against reported abatement, which may be different from the real amount of abatement. The 'carbon revenue' of an agent $i$ therefore equals the 
amount of abatement $\boldsymbol{q}_{\boldsymbol{i}}$ multiplied by the carbon price $\boldsymbol{p}$ multiplied by the relative monitoring error, which is a function of monitoring uncertainty. The carbon revenue function is thus upward sloping and linear.

In existing monitoring rules, uncertainty is often estimated using confidence/precision intervals, a statistical measure of the reliability of an estimate. For example, $95 / 5$ confidence/precision interval means that there is a $95 \%$ chance that the true value lies within $+/-5 \%$ of the estimate. In order not to complicate the model unreasonably, we assume here that the reported amount of abatement is within two standard errors from the true abatement.

The relative monitoring error of agent $i$ thus equals $\mathbf{1}+\mathbf{2} \boldsymbol{u}_{\boldsymbol{i}} \times \boldsymbol{\varepsilon}_{\boldsymbol{i}} \cdot \boldsymbol{u}_{\boldsymbol{i}}$ is monitoring uncertainty, which is defined by a monitoring methodology and $\varepsilon_{i}$ is a stochastic variable that is independently and identically distributed according to the distribution function $Y$, which in turn is assumed to be centered on $0\left(\boldsymbol{E}\left(\boldsymbol{\varepsilon}_{\boldsymbol{i}}\right)=\right.$ $0)$ and to be contained within the $[-\mathbf{1} ; \mathbf{1}]$ interval. This implicitly assumes that monitoring is not biased. This assumption is realistic, because in most carbon pricing policies, monitoring reports are verified by third-party auditors that make sure that there is no cheating and that agents do not report biased data (Bellassen et al. 2015). Depending on the monitoring rules set by the regulator, an agent may or may not choose the level of monitoring uncertainty $\boldsymbol{u}_{\boldsymbol{i}}>\mathbf{0}$. We start with an uncertainty level $\forall \boldsymbol{i}, \boldsymbol{u}_{\boldsymbol{i}}=\boldsymbol{u}$ prescribed by the regulator. Alternative monitoring rules are assessed after section 4.2.1.

Some GHG abatement projects may have other revenues not related to the carbon pricing policy, such as for example revenues stemming from electricity savings from improved energy efficiency on an industrial site. These 'non-carbon' revenues can be expressed as a product of abatement $\boldsymbol{q}_{\boldsymbol{i}}$ and a constant parameter $\boldsymbol{b}$ such as, for example, the price of electricity. The non-carbon revenue function is thus upward sloping, linear and independent of monitoring uncertainty. Taking into account non-carbon revenues is important, since it may significantly alter the outcomes in a voluntary carbon pricing scheme as demonstrated by two different project types in Section 4.

Direct costs of abatement are described as the sum of fixed costs $\boldsymbol{c}_{\mathbf{0}}$ and the amount of abatement $\boldsymbol{q}_{\boldsymbol{i}}$ squared and multiplied by a constant parameter $\boldsymbol{c}$. Marginal costs of abatement thus increase linearly with the amount of emissions reduced, which means that the cost function is upward-sloping and convex. This is coherent with the simplest assumption used in environmental economics (e.g. Weitzman 1974) and backed in practice by Marginal Abatement Cost Curves (MACCs) that are often used to illustrate GHG abatement costs (e.g. Castro 2012; Shishlov and Bellassen 2014a). 
Indirect (monitoring) costs of abatement are represented by a constant parameter $\boldsymbol{m}$ divided by the square of monitoring uncertainty $\boldsymbol{u}_{\boldsymbol{i}}$. Monitoring costs are thus inversely proportional to monitoring uncertainty, which appears logical - better information comes at a higher cost - and coherent with the available empirical research (e.g. Powell 1999; Antle et al. 2003). The monitoring costs function is therefore downward sloping and convex.

\subsection{Agent's and regulator's objectives}

Given the assumptions above, the profit function of an agent $\boldsymbol{i}$ can be written as:

$$
\max _{q_{i} \geq 0}\left(\pi_{i}\right)=p \times q_{i} \times\left(1+2 u \times \varepsilon_{i}\right)+b \times q_{i}-c_{0}-c \times q_{i}{ }^{2}-\frac{m}{u^{2}} ; \text { where } \varepsilon_{i} \in[-1 ; 1](1)
$$

The objective of a benevolent climate regulator in a carbon pricing policy - tax or an ETS - is to induce agents to produce the amount of abatement that maximizes the difference between total benefits and costs. In order to test the efficiency and distributional effects of monitoring uncertainty, we represent the heterogeneity of agents with two extremes balancing one another. Agent 1 benefits from monitoring uncertainty, i.e. $\boldsymbol{\varepsilon}_{\mathbf{1}}=\mathbf{1}$, while agent 2 is penalized by monitoring uncertainty, i.e. $\boldsymbol{\varepsilon}_{\mathbf{2}}=-\mathbf{1}$. We prefer a two-agent framework over a continuum of agents because it allows for simpler calculations and graphical illustrations of results (see Section 4). We demonstrate that using a continuous representation of agents' heterogeneity does not affect the nature of our findings (see Appendix 6). In a scheme with two agents the regulator's objective (welfare) function can therefore be written as:

$$
\max _{u>0}\left\{W=\sum_{i=1}^{2}\left(p \times q_{i}+b \times q_{i}-c_{0}-c \times{q_{i}}^{2}-\frac{m}{u^{2}}\right)\right\}(2)
$$

Similarly to Montero (2005), social welfare is the sole objective of the regulator and wealth transfers between regulator and agents do not directly impact the regulator choice. We nevertheless report the amount of undue transfers (UT) between regulator and agents, that is payments from the regulator above $(\mathrm{UT}>0)$ or below $(\mathrm{UT}<0)$ the value of the agent's abatement.

\subsection{Information scenarios}

It can reasonably be assumed that the regulator knows the reported GHG abatement of each agent $\boldsymbol{q}_{\boldsymbol{i}} \times$ $\left(1+2 u_{i} \times \varepsilon_{i}\right)$ and the level of monitoring uncertainty $\boldsymbol{u}_{i}$, but not the value of $\varepsilon_{i}$. Indeed, for many of the variables used in the calculations, a default average value and its uncertainty range, both scientifically established, are actually prescribed by the regulator (Bellassen and Stephan 2015). Compliance of agents 
with the uncertainty provisions is verified by independent auditors. The case of deliberate data falsification beyond the allowed monitoring uncertainty $\boldsymbol{u}_{\boldsymbol{i}}$ is therefore not considered here.

On the part of the agent, three information scenarios can be considered:

1. No information asymmetry. Similar to the regulator, the agents know the reported GHG abatement $\boldsymbol{q}_{\boldsymbol{i}} \times\left(\mathbf{1}+\mathbf{2} \boldsymbol{u}_{\boldsymbol{i}} \times \boldsymbol{\varepsilon}_{\boldsymbol{i}}\right)$ and the level of monitoring uncertainty $\boldsymbol{u}_{\boldsymbol{i}}$, but they do not know their type, that is the value of $\varepsilon_{\boldsymbol{i}}$. The agents thus cannot anticipate whether the monitoring error will result in overestimation (when $\mathbf{0}<\boldsymbol{\varepsilon}_{\boldsymbol{i}} \leq \mathbf{1}$ ) or underestimation (when $\mathbf{- 1} \leq \boldsymbol{\varepsilon}_{\boldsymbol{i}}<\mathbf{0}$ ) of GHG abatement. This scenario can happen in practice when the measurement error comes from a miscalibrated meter for example.

2. Information asymmetry. Unlike the regulator, the agents have perfect information on both the actual abatement $\boldsymbol{q}_{\boldsymbol{i}}$ and the monitoring error. Knowing whether $\boldsymbol{\varepsilon}_{\boldsymbol{i}}$ is positive or negative they can thus anticipate whether their abatement will be over- or underestimated. As a result, they can adapt their level of abatement $\boldsymbol{q}_{\boldsymbol{i}}$ and if allowed monitoring uncertainty $\boldsymbol{u}_{\boldsymbol{i}}$ according to this perfect anticipation. In practice, this scenario can occur in monitoring methodologies that use a default value for some parameter, such as the non-combustible fraction of fuel or flare efficiency. For example, the operator of a power plant may know that their state-of-the art installation has a lower non-combustible fraction than the default value used in the prescribed monitoring method, thus putting their emissions at the lower end of the uncertainty range.

3. Information bias. In this scenario, the agents not only have perfect information about the GHG abatement $\boldsymbol{q}_{\boldsymbol{i}}$ and the monitoring error $\left(\mathbf{1}+\mathbf{2} \boldsymbol{u}_{\boldsymbol{i}} \times \boldsymbol{\varepsilon}_{\boldsymbol{i}}\right)$, but are also able to tweak the measurement without breaking the letter of the rules laid down in the monitoring methodology ${ }^{1}$. As a result, the agents are still compliant, and the monitoring error therefore remains within the uncertainty range $\boldsymbol{u}_{\boldsymbol{i}}$ allowed by the regulator, but falls on its upper bound i.e. $\boldsymbol{\varepsilon}_{\boldsymbol{i}}=\mathbf{1}$ for all $\mathrm{i}$. This might happen for example if the monitoring is done using a meter installed at a chimney (Dimopoulos 2015). The regulator knows the maximum error when this method of monitoring follows an existing norm (e.g. EN 14181). The position of the meter within the chimney affects the measurement and the project developer may have private information on where to position the meter in order to obtain a measurement of emissions at the lower range of uncertainty. This may not sound very likely, but the recent scandals in the automotive industry make this scenario worth studying. Indeed, Volkswagen

\footnotetext{
${ }^{1}$ Note that in this last scenario, we revoke the "no bias" assumption laid out in section 3.1.
} 
allegedly installed software that constrained engine power during the emissions tests. This allowed for the tested car to behave at the 'eco-friendly' end of the 'eco-friendly' to 'power-hungry' range of real car drivers' behavior (The Economist 2015).

\subsection{Empirical data}

In addition to solving the model analytically, empirical data is plugged into the model to illustrate the behavior of functions graphically. The aim of this exercise is not to design a model optimally fitting the empirical data - this could be a topic for a separate article - but rather to use sensible figures to get an idea of the orders of magnitude of welfare transfers and losses that can reasonably be expected, and how these are impacted by information asymmetry. To this end, we will use the data publicly available for energy efficiency (EE) and landfill gas flaring (LFG) CDM projects, assuming that they represent typical investments into GHG abatement (please refer to Appendix 1 for details regarding empirical values).

\section{Results}

Similar to Montero (2000), we model a two-step game where the regulator sets the rules - i.e. carbon price and monitoring uncertainty policy - and then agents choose their levels of abatement production $\boldsymbol{q}_{\boldsymbol{i}}$ and, if allowed, the level of monitoring uncertainty $\boldsymbol{u}_{\boldsymbol{i}}$ striving to maximize their profit. For each case, the model is solved analytically when possible and numerically for two case-studies - EE and LFG - otherwise. Calculus details are provided in Appendix 5. In order to better understand the mechanisms and trade-offs involved, we also illustrate the results graphically.

\subsection{Scenario 1: uncertainty with no information asymmetry}

Without risk sensitivity, both the agents and the regulator will behave based on the expected value of monitored GHG abatement $\boldsymbol{E}\left[\boldsymbol{q}_{\boldsymbol{i}} \times\left(\mathbf{1}+\mathbf{2} \boldsymbol{u}_{\boldsymbol{i}} \times \boldsymbol{\varepsilon}_{\boldsymbol{i}}\right)\right]=\boldsymbol{q}_{\boldsymbol{i}}$. In the absence of information asymmetry the agent's and the regulator's objectives are thus aligned with regards to the value of $\boldsymbol{u}_{\boldsymbol{i}}$ : monitoring uncertainty affects only the costs part of both regulator's and agents' objective functions. The optimal monitoring uncertainty is therefore $\boldsymbol{u}_{\boldsymbol{i}}{ }^{*}=+\infty$, no matter who decides on its value. A rational agent will then produce the amount of GHG abatement $\boldsymbol{q}_{i}{ }^{*}$ that maximizes its profit function - in other words when the marginal benefits equal the marginal costs:

$$
\frac{\partial \pi_{i}}{\partial q_{i}}=p+b-2 c q_{i}=0
$$




$$
\Leftrightarrow \boldsymbol{q}_{i}{ }^{*}=\frac{p+b}{2 c}
$$

The resulting total welfare in a two-agent framework is then:

$$
W^{*}=\frac{(p+b)^{2}}{2 c}-2 c_{0}
$$

While the abatement of individual agents is misestimated, the overall abatement estimation is accurate. Mathematically, the regulator therefore has no reason to limit monitoring uncertainty, as long as the error is random and not anticipated by the agent. At the same time, individual over- and underestimations will lead to unjust distribution of benefits among agents. The undue transfers (UT) will therefore be:

$$
U T=\sum_{i=1}^{2}\left(p \times q_{i} \times 2 u_{i}\right)=+\infty
$$

Plugging the empirical values from Section 3.4 into the model results in the optimal production of $9.06 \mathrm{Mt}$ $\mathrm{CO}_{2} \mathrm{e}$ of emissions reductions by each agent for the EE project and $0.27 \mathrm{Mt} \mathrm{CO}_{2} \mathrm{e}$ for the LFG project, no matter the regulator's stringency on a possible maximum value of $\boldsymbol{u}_{\boldsymbol{i}}$ (Figure 1 and Figure 2). In the absence of information asymmetry, the rules regarding monitoring uncertainty do not affect the amount of abatement, as the quantity of emissions reductions produced is independent of the monitoring error. As a result, the best regulation in this information configuration is to have no requirement on uncertainty. This is consistent with the formalism of Chakraborty and McAfee (2014): when the damage function is linear and under perfect information, the penalty need not be adjusted for monitoring uncertainty.

\section{Figure 1 - No information asymmetry (EE)}
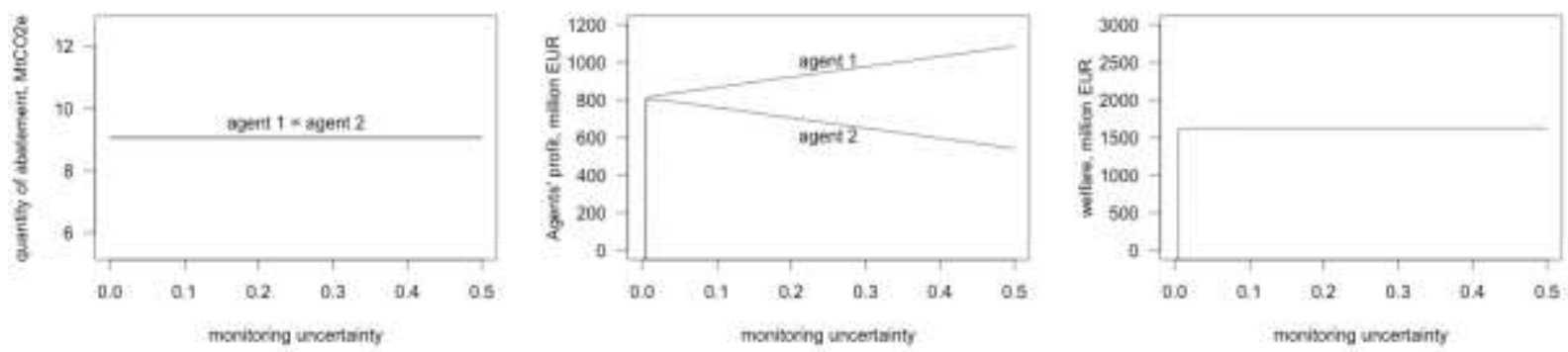

Figure 2 - No information asymmetry (LFG) 

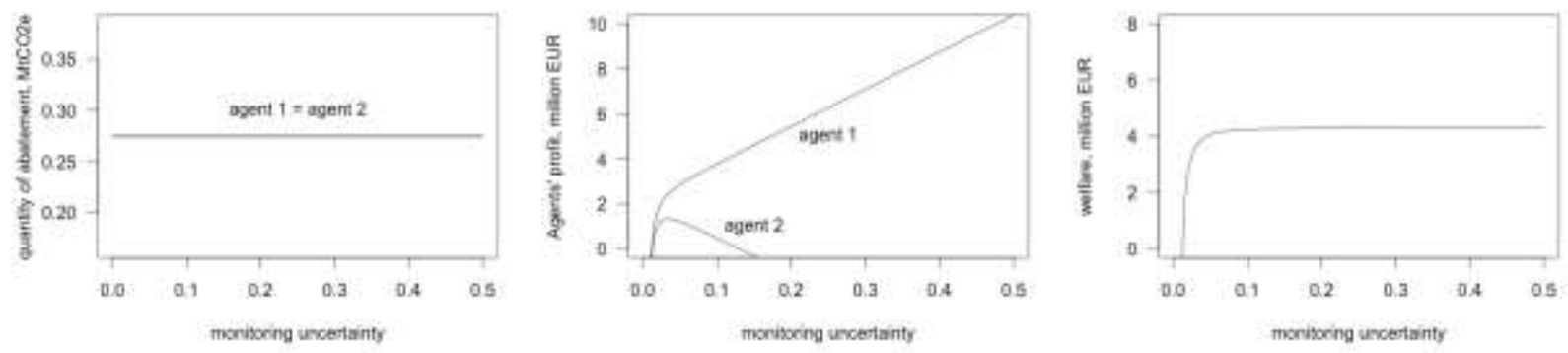

This result can be questioned for very small (<1\%) and very large uncertainties (e.g. $>50 \%)$ if multiple rounds are considered. As the monitoring error approaches $0 \%$ the investment in GHG abatement becomes unprofitable, which leads either to negative - without profitability constraint - or null - with a profitability constraint - profits and welfare. This effect is stronger for investments with no revenues, other than carbon, such as LFG projects. Similarly, prescribing very high uncertainty may render the agent that underestimates abatement unprofitable. This can be observed in the LFG case with uncertainty above $15 \%$ (Figure 2Erreur! Source du renvoi introuvable.). Considering that climate mitigation is usually a minor component of firms' turnover, we did not impose a profitability constraint. Yet, we discuss the policy implications of negative profits in the case of opt-in climate policies in section 4.2.

\subsection{Scenario 2: information asymmetry}

Let us now assume that there is information asymmetry, i.e. agents can anticipate the monitoring error $\boldsymbol{\varepsilon}_{\boldsymbol{i}}$ and adjust their level of abatement production $\boldsymbol{q}_{\boldsymbol{i}}$ accordingly. The optimal solution for agents is then:

$$
\begin{gathered}
\frac{\partial \pi_{i}}{\partial q_{i}}=p \times\left(1+2 u_{i} \times \varepsilon_{i}\right)+b-2 c q_{i} \\
q_{i}^{*}=\frac{p \times\left(1+2 u_{i} \times \varepsilon_{i}\right)+b}{2 c} ; \text { where } \varepsilon_{i} \in[-1 ; 1]
\end{gathered}
$$

The agents will thus produce suboptimal levels of abatement compared to the scenario with no asymmetry. The larger the uncertainty, the further the agents will be from the optimal production level. In order to address this issue the regulator can set monitoring rules pertaining to this uncertainty. Based on the previous research regarding the treatment of monitoring uncertainty in climate policy (Bellassen et al. 2015; Shishlov and Bellassen 2015) the regulator has three realistic policy options to deal with monitoring uncertainty: 
a) Prescribing $\boldsymbol{u}$ through a specific monitoring method - for example through a prescribed monitoring method and default values.

b) Setting a maximum tolerated threshold for $\boldsymbol{u}$, as it is done in the EU ETS (Warnecke 2014) or in the Standard for Sampling and Surveys of the CDM (Shishlov and Bellassen 2015), which sets the maximum tolerated monitoring error at $5 \%$ or $10 \%$ for samples and surveys.

c) Applying a discount to carbon payments (or an increase in carbon tax) proportional to $\boldsymbol{u}$. This approach is applied for certain types of CDM projects, e.g. forestry, and in some other carbon offset standards, e.g. CCX and VCS (Shishlov and Bellassen 2015).

\subsubsection{Policy option a - prescribing uncertainty}

If the regulator prescribes uncertainty, the optimal solution for this prescribed uncertainty level is:

$$
\begin{gathered}
u^{*}=\sqrt[4]{\frac{c m}{p^{2}}} \\
W^{*}=\frac{(p+b)^{2}}{2 c}-2 c_{0}-\frac{4 p m}{\sqrt{c m}} \\
U T=\sum_{i=1}^{2}\left(p \times q_{i} \times 2 \sqrt[4]{\frac{c m}{p^{2}}}\right)=4 \sqrt{p} \times q_{i} \times \sqrt[4]{c m}
\end{gathered}
$$

In the presence of information asymmetry, an optimal and non-infinite $\boldsymbol{u}^{*}$ emerges. Indeed, the agent with overestimated emissions reductions abates more than optimal, producing more costly abatement than what the agent with underestimated emissions reductions would have produced in his stead without information asymmetry. This, together with additional monitoring costs related to the prescribed finite error, results in a welfare loss of $-\frac{4 p m}{\sqrt{c m}}$ compared to the absence of information asymmetry, a classic example of the consequences of adverse selection in the information asymmetry context. Note that representing the problem by a continuum of uniformly distributed agents rather than by two opposite agents leads to similar results (Appendix 6): a non-infinite optimal $\boldsymbol{u}^{*}$ also emerges to balance adverse selection and monitoring costs. This is $\boldsymbol{u}^{*}$ turns out to be $30 \%$ higher and the welfare loss is therefore slightly lower. 
The model thus demonstrates that the heterogeneity in benefits - similarly to the heterogeneity in costs more generally studied in the literature (see for example Laffont and Tirole 1993) - under asymmetric information results in suboptimal levels of production.

Plugging the empirical values from Section 3.4 into the model results in an optimal $\boldsymbol{u}^{*}$ of $4.27 \%$ and $6.53 \%$ for EE and LFG project types respectively. In the case of EE, Agent 1 produces $9.19 \mathrm{Mt} \mathrm{CO}_{2} \mathrm{e}$ of emissions reductions and Agent 2 produces only $8.93 \mathrm{Mt} \mathrm{CO}_{2} \mathrm{e}$ (Figure 3). In the case of LFG, Agent 1 produces 0.31 $\mathrm{Mt} \mathrm{CO}_{2} \mathrm{e}$ of emissions reductions and Agent 2 produces only $0.24 \mathrm{Mt} \mathrm{CO}_{2} \mathrm{e}$ (Figure 4). The welfare loss compared to the absence of information asymmetry is EUR0.66 million in the case of EE and EUR0.28 million in the case of LFG. This welfare loss comes from increased mitigation costs due to more costly abatement compared to the case with no asymmetry, as well as from the increased costs of monitoring, when a finite uncertainty is prescribed.

Figure 3 - Information asymmetry and monitoring error prescribed (EE)
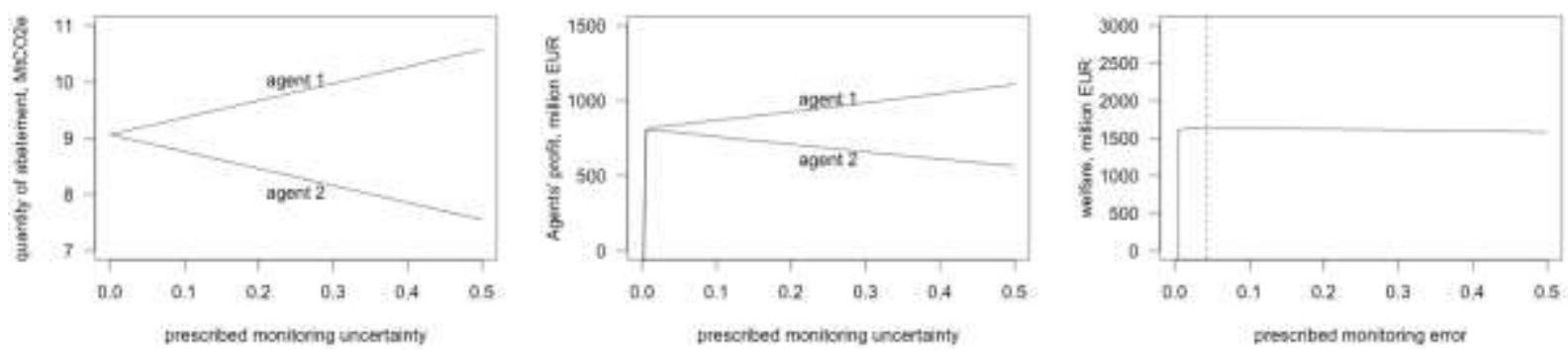

Figure 4 - Information asymmetry and monitoring error prescribed (LFG)
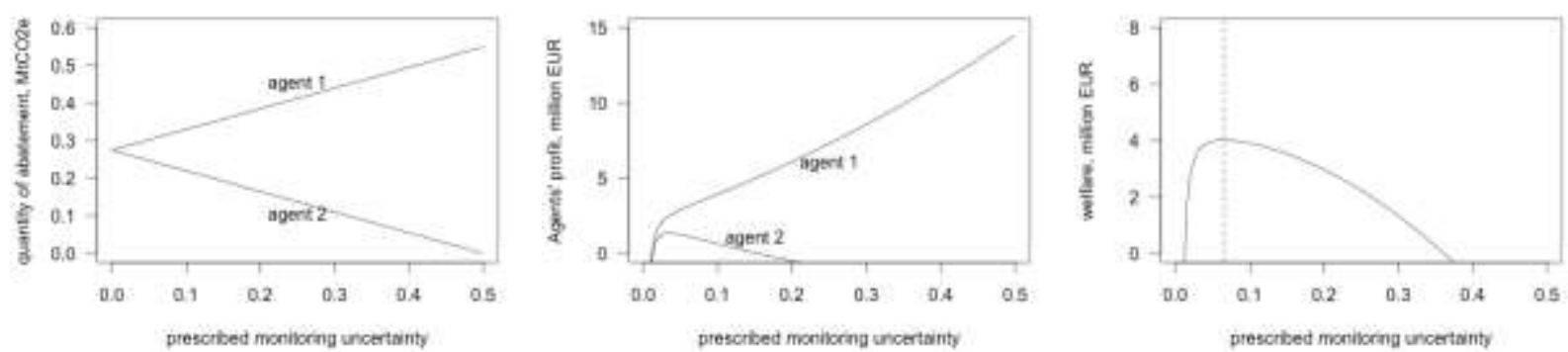

While the welfare loss in the case of EE is relatively small - around $0.04 \%$ - compared to the scenario with no asymmetry (Figure 3), the situation changes significantly in the instance of abatement projects with no benefits other than carbon, i.e. with $\boldsymbol{b}=\mathbf{0}$. Indeed, in the case of LFG the welfare loss compared to the case with no asymmetry reaches $6.49 \%$ at the optimal $\boldsymbol{u}=6.53 \%$ (Figure 4 ). 
Note that adding a profitability constraint - corresponding in practice to a carbon pricing mechanism in which participation is voluntary - such as the CDM - does not change the results for energy efficiency projects. Indeed, abatement is largely profitable for both agents around the optimal $\boldsymbol{u}^{*}$. In LFG projects, however, the profits of Agent 2 are close to zero. Indeed, should the regulator misjudge the optimal uncertainty, and prescribe an uncertainty higher than 15\%, Agent 2 becomes unprofitable. In a voluntary carbon pricing mechanism, prescribing uncertainty thus becomes much riskier. If Agent 2 does not opt-in, the welfare produced by his abatement - which is worth half the total welfare produced in Scenario 1 - is lost. Moreover, the amount of welfare transfer from the society to the agents would shoot up: as long as he participates, Agent 2 produces abatement for which he is not paid, which partly compensates for the payments made to Agent 1 for abatement that is overestimated.

\subsubsection{Policy option $b$ - uncertainty threshold}

If the regulator prescribes the maximum allowed uncertainty threshold $\boldsymbol{t} \geq \boldsymbol{u}_{\boldsymbol{i}}$, the agents get a limited degree of flexibility in choosing their monitoring uncertainty. Given the profit functions of the agents discussed earlier, it is quite obvious that Agent 1 has the incentive to increase the uncertainty until the maximum level allowed. For Agent 2, however, there is a non-infinite optimal level of uncertainty, which may be below or above the threshold set by the regulator:

$$
\begin{gathered}
\boldsymbol{u}_{1}{ }^{*}=t, q_{1}{ }^{*}=\frac{p \times(1+2 t)+b}{2 c} \\
u_{2}{ }^{*}=\min \left(\sqrt[3]{\frac{m}{p q_{2}}}, t\right)
\end{gathered}
$$

As $\boldsymbol{u}_{2}{ }^{*}$ is a non-trivial function of $\boldsymbol{q}_{2}$, there is no obvious analytical solution for $\boldsymbol{q}_{2}{ }^{*}$. Yet, as shown in the numerical simulation (Figure 5 and Figure 6), Agent 2 abates $9.03 \mathrm{Mt} \mathrm{CO2e} \mathrm{(EE)} \mathrm{and} \mathrm{0.26} \mathrm{Mt} \mathrm{CO2e} \mathrm{(LFG),}$ which is slightly more than the respective amounts in case of policy option a. At the same time Agent 2 invests in monitoring uncertainty $\boldsymbol{u}_{2}{ }^{*}$ of $1.03 \%$ (EE) and $3.39 \%$ (LFG), lower than $\boldsymbol{t}^{*}$ of $4.27 \%$ and $6.53 \%$ respectively. This indeed reduces his penalty - that is the amount of abatement, for which he is not rewarded due to the monitoring error. Note that $t^{*}$ is in both cases very close to the optimal prescribed $\boldsymbol{u}^{*}$ of case 2a. As a result, Agent 1 produces the same amounts of $9.19 \mathrm{Mt}$ CO2e (EE) and $0.31 \mathrm{Mt}$ CO2e (LFG) as in the previous case. The welfare loss compared to the scenario with no information asymmetry is EUR3.1 million or around $0.19 \%$ in the case of EE and EUR0.42 million or around $9.72 \%$ in the case of LFG, which occurs due to increased costs of monitoring of Agent 2. 
Figure 5 - Outcomes with information asymmetry and maximum uncertainty threshold (EE)
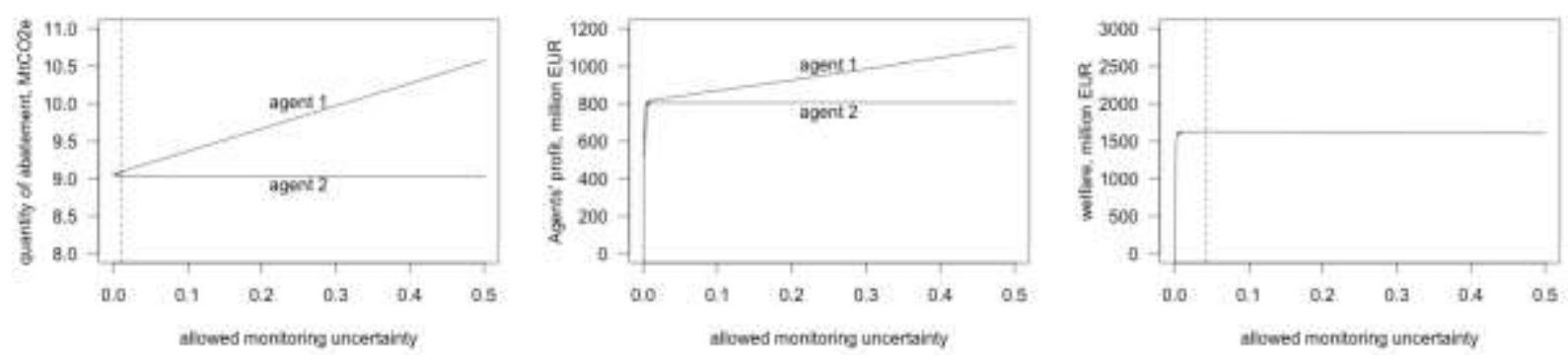

Figure 6 - Outcomes with information asymmetry and maximum uncertainty threshold (LFG)
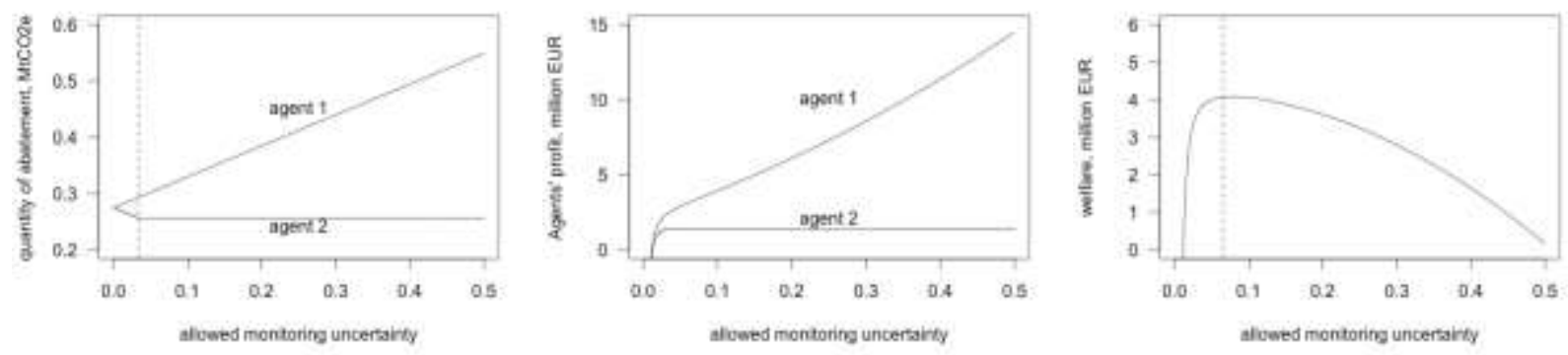

The welfare loss would be even more pronounced if the regulator does not set $\mathbf{t}^{*}$ properly. For example, with the threshold set at $\mathbf{t}=\mathbf{2 0 \%}$ the welfare loss reaches $0.4 \%$ (EE) and $\mathbf{2 2 \%}$ (LFG) respectively. This happens due to increased costs of abatement of Agent 1. Similarly to the previous scenario, the effects of information asymmetry are much more pronounced in the case with no revenue other than carbon.

Again, adding a profitability constraint would not alter the results for EE projects. In the case of LFG projects, the risk that Agent 2 is not profitable is substantially reduced. Indeed, he is able to invest in monitoring and avoid overly large amounts of unpaid emissions reductions. Thus, even if the regulator mistakenly sets a too high uncertainty threshold, Agent 2 is able to remain profitable.

\subsubsection{Policy option c - discounting for uncertainty}

Let us now consider the option where the regulator applies a discount $\boldsymbol{\beta}$ proportional to monitoring uncertainty $\boldsymbol{u}_{\boldsymbol{i}}$. The optimal solution for agents then becomes:

$$
q_{i}^{*}=\frac{p \times\left(1+2 u_{i} \times \varepsilon_{i}\right) \times(1-\beta)+b}{2 c}
$$


Both agents thus receive an explicit incentive to reduce the monitoring uncertainty, the strength of which depends on the discounting coefficient $\boldsymbol{\beta}$. Again, in this case there is no obvious analytical solution for $\boldsymbol{u}_{\boldsymbol{i}}$. Plugging the empirical values from Section 3.4 into the model results in an optimal $\boldsymbol{\beta}^{*}$ of 1.17 and 1.21 for EE and LFG projects respectively.

Introducing a discount proportional to uncertainty strongly affects the monitoring behavior of Agent 1 , while the impact on Agent 2 is minor (Figure 7) compared to previous scenarios. With the optimal $\boldsymbol{\beta}^{*}$ of 1.17 and 1.21 for EE and LFG projects respectively, Agent 1 invests in monitoring uncertainty of 17-18\%, while Agent 2 further reduces uncertainty to avoid stronger penalty.

\section{Figure 7 - Agents' profits with information asymmetry and discounting}
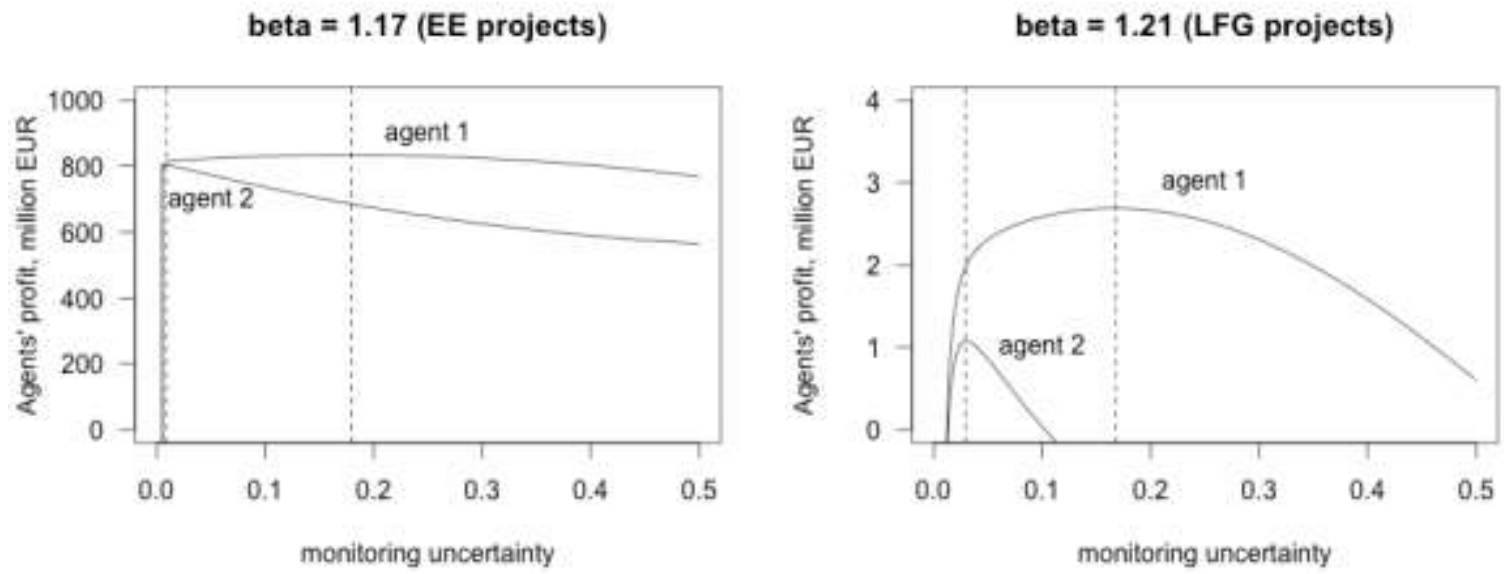

The welfare loss compared to the case with no information asymmetry is EUR3.9 million or around $0.24 \%$ in the case of EE and EUR0.40 million or around 9.34\% in the case of LFG, i.e. close to the option with an uncertainty threshold. This happens due to higher abatement costs of Agent 1 and higher monitoring costs of Agent 2. Although Agent 2 only slightly reduces his error compared to other scenarios, marginal cost of doing it is increasing as he approaches very low levels of $\boldsymbol{u}_{\boldsymbol{i}}$. One of the advantages of the discounting approach is that the regulator does not have to figure out the optimal error to prescribe or the optimal uncertainty threshold to set, instead offering the agents flexibility to choose the intensity of monitoring based on their cost considerations.

\subsection{Scenario 3: information bias}

To represent the scenario where agents are able to influence the measurement within the uncertainty range, we assume that the reported emissions reductions fall on the upper end of the uncertainty range 
for both agents, i.e. $\boldsymbol{\varepsilon}_{\boldsymbol{i}}=\mathbf{1}$. Similar to Agent 1 in scenario 2 , both agents thus have an implicit incentive to increase uncertainty to benefit from overestimated emissions reductions.

In this information scenario, policy options (a) and (b) - namely prescribing monitoring uncertainty or setting a maximum allowed uncertainty threshold - come down to the same thing, since agents will always choose the maximum uncertainty allowed. The optimal solution is then:

$$
\begin{gathered}
u_{i}{ }^{*}=\sqrt[4]{\frac{c m}{p^{2}}} \\
{q_{i}}^{*}=\frac{p \times\left(1+2 u_{i} \times \varepsilon_{i}\right)+b}{2 c} ; \text { where } \varepsilon_{i}=1
\end{gathered}
$$

The welfare then becomes:

$$
W^{*}=\frac{(p+b)^{2}}{2 c}-2 c_{0}-\frac{4 p m}{\sqrt{c m}}
$$

And the undue wealth transfers (UT) are:

$$
U T=\sum_{i=1}^{2}\left(2 p \times q_{i} \times \sqrt[4]{\frac{c m}{p^{2}}}\right)=4 \sqrt{p} \times q_{i} \times \sqrt[4]{\mathrm{cm}}
$$

In policy option c the optimal solution for both agents is:

$$
q_{i}^{*}=\frac{p \times\left(1+2 u_{i} \times \varepsilon_{i}\right) \times(1-\beta)+b}{2 c} ; \text { where } \varepsilon_{i}=1
$$

The optimal solution for the regulator is therefore to apply a discount $\boldsymbol{\beta}=\mathbf{1} /\left(\boldsymbol{u}_{\boldsymbol{i}}+\mathbf{0 . 5}\right)$ that effectively brings the level of abatement to the first-best, i.e. the same as with no information asymmetry:

$$
\begin{gathered}
\boldsymbol{q}_{\mathrm{i}}{ }^{*}=\frac{\boldsymbol{p}+\boldsymbol{b}}{2 \boldsymbol{c}} \\
\boldsymbol{u}_{\mathrm{i}}{ }^{*}=+\infty \\
\boldsymbol{W}^{*}=\frac{(\boldsymbol{p}+\boldsymbol{b})^{2}}{2 \boldsymbol{c}}-2 c_{0}
\end{gathered}
$$

Moreover, the discount allows countering the effect of uncertainty thus canceling out the undue transfers. While the information scenario $\mathbf{3}$ is unlikely in practice due to the third-party verification, the possibility 
of measurement influence by the agent further reinforces the conclusion that the regulator shall limit uncertainty in order to ensure the economic and environmental efficiency of climate policy. Interestingly, in this case applying a discount proportional to uncertainty is preferable to setting minimum certainty thresholds or prescribing the error. The optimal discount $\beta=1 /\left(u_{i}+\mathbf{0 . 5}\right)$ that effectively cancels out the negative effects of overestimation when all agents are able to tweak the monitored value to the upper end of the uncertainty range can be seen as maximum discount to be applied as well as the value that guarantees the absence of overpaid emissions reductions.

\section{Synthesis and discussion}

\subsection{Policy choices to maximize welfare}

Analytical results of our model are synthetized in Appendix 2. These results demonstrate that under the simplest set of assumptions, i.e. no information asymmetry and random monitoring errors (Scenario 1), the first-best level of abatement is achieved without imposing any constraints on monitoring uncertainty. As a result, the best regulation is to have no special requirements on uncertainty as long as the monitored value is accurate, that is as long as expected value is the true amount of emissions reductions for the whole population of agents.

Conversely, when there is information asymmetry (Scenario 2), the agents with overestimated emissions reductions are over-rewarded for their abatement and therefore abate more than optimal. The reverse is true for agents whose abatement is underestimated. This situation is a generalization of the classic example of the adverse selection in the information asymmetry context where over-abatement is driven by information asymmetry on the agent's abatement costs (Laffont and Tirole 1993) rather than on the level of abatement produced by the agent (our case). Limiting monitoring uncertainty allows the regulator to reduce the excessive participation of overestimating Type 1 agents and increase the insufficient participation of underestimating Type 2 agents. The regulator thus has to find a balance between the stringency of monitoring requirements which optimizes the participation of each agent and the additional costs this stringency imposes. If the agents are able to tweak the monitoring within the uncertainty limits (Scenario 3), offering a menu of contracts through a discount proportional to monitoring uncertainty is the best policy choice.

\subsection{Mitigating non-participation risk in voluntary mechanisms}

Numerical simulations (Appendix 3 and Appendix 4) demonstrate that prescribing the level of uncertainty under information asymmetry (case $\mathbf{2} \boldsymbol{a}$ ) is better than the two other policy options (cases $\mathbf{2} \boldsymbol{b}$ and $\mathbf{2 c}$ ) in 
terms of welfare outcomes. This approach, however, relies heavily on the accuracy of the regulator's information regarding the profit functions of the agents. Indeed, in the case of LFG if the regulator mistakenly prescribes an error above $15 \%$, the investment in abatement becomes unprofitable for Agent 2 (Section 4.2.1). In a voluntary scheme this would result in halving the welfare because Agent 2 would not participate. Setting a minimum certainty threshold (case $\mathbf{2 b}$ ) or discounting for uncertainty (case $\mathbf{2 c}$ ) mitigates this risk as Agent 2 is allowed to invest in monitoring in order become profitable again. In our numerical applications, total welfare is comparable for the two cases, case $\mathbf{2} \boldsymbol{b}$ being slightly closer to the optimum for EE projects and case $\mathbf{2} \boldsymbol{c}$ being slightly closer to the optimum for LFG projects.

\subsection{Undue wealth transfers}

While case 1a optimizes total welfare, it results in large amounts of undue transfers from society to agents (UT) - positive for Agent 1 and negative for Agent 2. In practice, this may impair the acceptability of the carbon pricing mechanism. Under the information asymmetry scenario moving from case $\mathbf{2} \boldsymbol{a}$ to $\mathbf{2} \boldsymbol{b}$ and to $2 c$, the regulator decreases the risk by providing agents with flexibility to choose their monitoring errors, but increases net undue wealth transfer from society to agents (Appendix 3 and Appendix 4). The optimal solution ultimately depends on cases and on how important it is to limit undue transfers in the eyes of agents, regulator and society. In LFG, discounting increases welfare compared to maximum uncertainty thresholds, with a 'manageable' level of UT increase, while in EE, discounting decreases welfare compared to maximum uncertainty, and UT skyrockets. As demonstrated in case $\mathbf{3 c}$, applying a discount of $\boldsymbol{\beta}=$ $1 /\left(u_{i}+0.5\right)$ effectively safeguards the regulator from rewarding overestimated emissions reductions. In case $\mathbf{2 c}$, however, getting this certainty on a net wealth transfer comes at an unknown price in reduced total welfare.

\subsection{Decision tree for setting rules on monitoring uncertainty}

The key policy recommendations stemming from our analysis can be summarized in a decision tree below (Figure 8). In a nutshell, the regulator has to check whether information asymmetry is likely for a reasonable prescribed uncertainty threshold (indirectly coming from the default parameters). If not, there is no need to add further requirements or incentives on monitoring uncertainty. This result can be questioned for large uncertainties, which undermine the assumption of insensibility to risk. For example, an agent for which abatement is being largely underestimated may go bankrupt due to his miscalculation and as a result stop reducing emissions, as demonstrated on the example of LFG projects with uncertainty 
of over $15 \%$. This would bias the set of agents towards those whose abatement is being overestimated. An arbitrary choice of a reasonable tolerated uncertainty range may therefore be warranted.

When information asymmetry is likely, the regulator should introduce special rules to limit uncertainty. Setting a maximum monitoring error threshold or applying a discount is the best default approach for voluntary schemes for two reasons. First, information asymmetry is very likely as agents who voluntarily opt in are likely to be well-informed - at least they are informed enough to have weighed their expected costs and benefits from such a decision. Second, the profitability constraint which applies to voluntary schemes makes it paramount that most agents whose abatement is underestimated remain profitable. In such schemes, participation is indeed critical both for reaching a high level of total welfare and for limiting the amount of net undue transfers - as the negative undue transfers to underestimated agents partly offsets the positive ones to overestimated agents.

Figure 8 - Regulator's decision to set rules regarding monitoring uncertainty

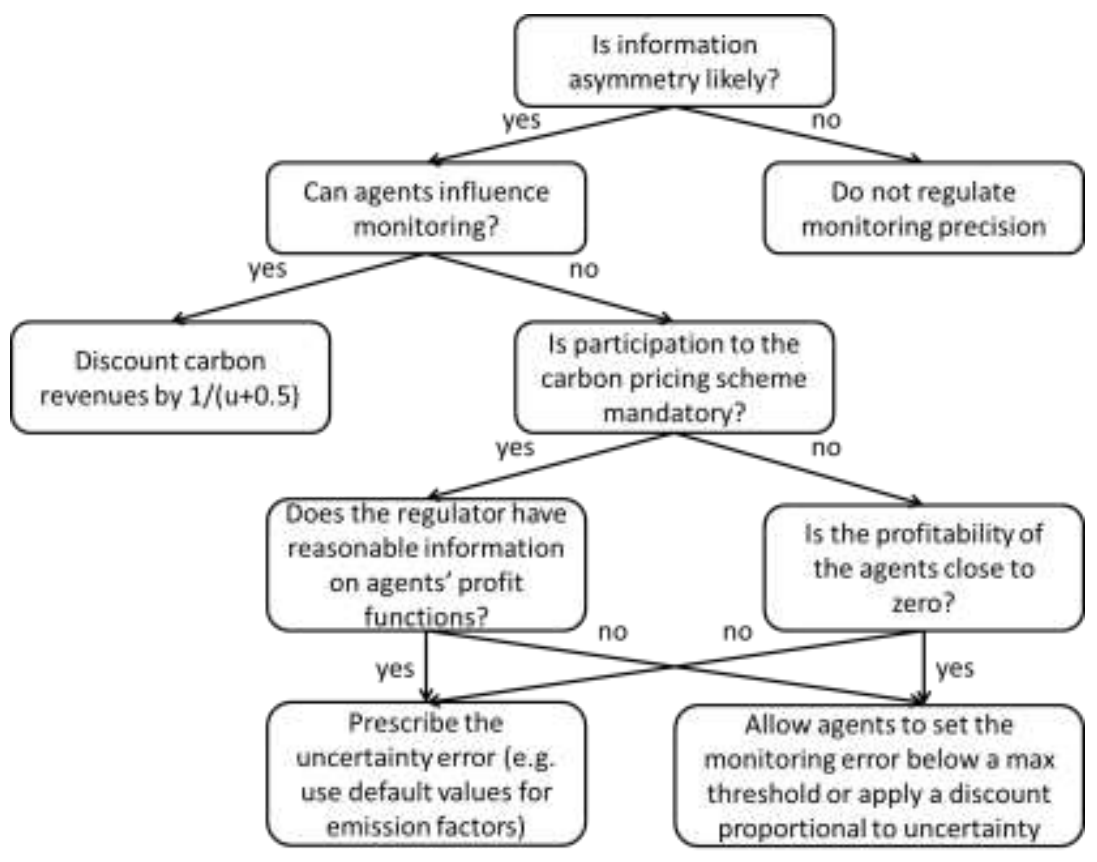

\section{Conclusions and policy recommendations}

In this article we investigated the effects of monitoring policy choice on economic and environmental outcomes of climate policy. It was demonstrated that under the simplest set of assumptions - no information asymmetry and random monitoring errors - the first-best level of abatement is achieved without imposing any constraints on monitoring uncertainty. However, in the presence of information asymmetry, monitoring uncertainty may hamper the economic and environmental performance of climate 
policy due to adverse selection. Monitoring uncertainty under information asymmetry, which results in heterogeneity in the agents' benefits from abatement, generalizes the classical trade-off between production efficiency and information rents (e.g. Laffont and Tirole 1993).

In choosing the monitoring policy to address uncertainty - prescribing the error, setting maximum uncertainty thresholds or applying a discount - the regulator has to balance welfare, risk and undue wealth transfers. In a mandatory scheme, prescribing uncertainty is preferable if the regulator focuses on maximizing welfare. This option is also efficient in minimizing net wealth transfer, as transfers from underestimated agents largely offsets to overestimated agents. In a voluntary carbon pricing scheme, we find that allowing agents to set their own monitoring uncertainty below a maximum threshold or applying a discount proportional to monitoring uncertainty is preferable in order to limit the risk that underestimated agents opt out.

Our analysis thus partly supports the introduction of the Uncertainty Standard with discounting under the CDM that was proposed by the CDM Executive Board in 2012 (Shishlov and Bellassen 2015). Discounting is arguably better than prescribing uncertainty and allows, if desirable, to ensure that there is no undue wealth transfer from society to agents. However, using a minimum certainty threshold may provide a better trade-off between total welfare and undue wealth transfers if the regulator has enough information to set the threshold properly.

Alternatively, the discounting policy may be complemented with a minimum threshold to keep the uncertainty at a reasonable level to limit the adverse effects, e.g. not more than $10 \%$ in our cases. In fact, such a hybrid approach was proposed by Wartmann, Groenenberg, and Brockett (2009) to address monitoring uncertainty for potential Carbon Capture and Storage (CCS) sites under the EU ETS using the 'uncertainty supplement'. This supplement - in other words an upward adjustment of a site's emissions would be equal to the difference between the accuracy that a scheme can provide and the maximum uncertainty required by the Monitoring and Reporting Guidelines of the EU ETS. This approach would not ban sites with high monitoring uncertainty from participation in the scheme, yet it would encourage the development of more accurate monitoring techniques in the long-run.

While our analysis emphasized welfare optimization, the regulator may have other objectives or constraints, such as for example minimizing "undue" transfers to the agents misestimating their abatement or maximizing the difference between environmental benefits and net transfers from the regulator as in Canton et al. (2009). The extent to which the regulator knows about the agents' profit 
function - and therefore the extent to which he is able to set optimal uncertainty thresholds or discounts

- is also questionable. Exploring these scenarios would require further developments of the model to introduce a budgetary constraint and/or to relax the assumption of exogenous carbon price. We therefore stop here and let other researchers explore these avenues.

\section{Bibliography}

Antle, J., S. Capalbo, S. Mooney, E. Elliott, and K. Paustian. 2003. "Spatial Heterogeneity, Contract Design, and the Efficiency of Carbon Sequestration Policies for Agriculture." Journal of Environmental Economics and Management 46 (2): 231-50.

Becker, Gary S. 1968. "Crime and Punishment: An Economic Approach." Journal of Political Economy 76 (2): 169-217. doi:10.1086/259394.

Bellassen, V., and N. Stephan. 2015. Accounting for Carbon: Monitoring, Reporting and Verifying Emissions in the Climate Economy. Cambridge, UK: Cambridge University Press.

Bellassen, V., N. Stephan, M. Afriat, E. Alberola, A. Barker, J-P. Chang, C. Chiquet, et al. 2015. "Monitoring, Reporting and Verifying Emissions in the Climate Economy." Nature Climate Change 5 (4): 319-28.

Bento, Antonio M., Ravi Kanbur, and Benjamin Leard. 2015. "Designing Efficient Markets for Carbon Offsets with Distributional Constraints." Journal of Environmental Economics and Management 70 (March): 51-71. doi:10.1016/j.jeem.2014.10.003.

Brander, M., A. Sood, C. Wylie, A. Haughton, and J. Lovell. 2011. "Electricity-Specific Emission Factors for Grid Electricity." Technical Paper. Ecometrica.

Bultheel, C., R. Morel, H. Hainaut, M. Deheza, I. Shishlov, V. Depoues, and B. Leguet. 2015. "COP21 - a Successful 'end of the Beginning.'" Climate Brief \#38. I4CE - Institute for Climate Economics. http://www.i4ce.org/download/climatebrief_cop21/.

Canton, Joan, Stéphane De Cara, and Pierre-Alain Jayet. 2009. "Agri-Environmental Schemes: Adverse Selection, Information Structure and Delegation." Ecological Economics 68 (7): 2114-21. doi:10.1016/j.ecolecon.2009.02.007.

Castro, P. 2012. "Does the CDM Discourage Emission Reduction Targets in Advanced Developing Countries?" Climate Policy 12 (2): 198-218.

Chakraborty, I., and P. McAfee. 2014. "Let the Punishment Fit the Crime: Enforcement with Error." Journal of Public Economic Theory 16 (2): 274-92.

Dasgupta, P., P. Hammond, and E. Maskin. 1980. “On Imperfect Information and Optimal Pollution Control." The Review of Economic Studies 47 (5): 857-60. doi:10.2307/2296917.

Dimopoulos, C. 2015. "Chapter 10. Direct Measurement in the EU ETS." In Accounting for Carbon, Cambridge University Press, 313-38. Bellassen, V., Stephan, N.

EDF. 2013. "California. The World's Carbon Markets: A Case Study Guide to Emissions Trading." Environmental Defence Fund. http://www.ieta.org/assets/Reports/EmissionsTradingAroundTheWorld/edf_ieta_california_cas e_study_may_2013.pdf.

IEA. 2012. "Electricity Information." IEA Statistics. International Energy Agency.

Laffont, J-J., and J. Tirole. 1993. A Theory of Incentives in Procurement and Regulation. MIT Press. Cambridge, MA.

Montero, J.P. 1999. "Voluntary Compliance with Market Based Environmental Policy : Evidence from the U.S. Acid Rain Program." Journal of Political Economy 107 (5): 998-1033.

- - . 2000. "Optimal Design of a Phase-in Emissions Trading Program." Journal of Public Economics 75 (2): 273-91. 
- - . 2005. "Pollution Markets with Imperfectly Observed Emissions." RAND Journal of Economics 36 (3): 645-60.

Png, I. P. L. 1986. "Optimal Subsidies and Damages in the Presence of Judicial Error." International Review of Law and Economics 6 (1): 101-5. doi:10.1016/0144-8188(86)90042-6.

Powell, M. 1999. "Effect of Inventory Precision and Variance on the Estimated Number of Sample Plots and Inventory Variable Cost: The Noel Kempff Mercado Climate Action Project." Winrock International.

Segerson, K. 1988. "Uncertainty and Incentives for Nonpoint Pollution Control." Journal of Environmental Economics and Management 15: 87-98.

Shishlov, I. 2015. "Chapter 11. Trend Setter for Projects: The Clean Development Mechanism." In Accounting for Carbon, Cambridge University Press, 341-89. Bellassen, V., Stephan, N.

Shishlov, I., and V. Bellassen. 2014a. "Moving from the CDM to Various Approaches." CDC Climat. http://www.cdcclimat.com/Climate-Brief-no34-Moving-from-the.html.

- - . 2014b. "Review of Monitoring Uncertainty Requirements in the CDM." Working Paper 16. Paris: CDC Climat.

- - - 2015. "Review of the Experience with Monitoring Uncertainty Requirements in the Clean Development Mechanism." Climate Policy, 1-20.

The Economist. 2015. "Dirty Secrets." http://www.economist.com/news/leaders/21666226-volkswagensfalsification-pollution-tests-opens-door-very-different-car.

Turner, A., D. Jacob, J. Benmergui, S. Wofsy, J. Maasakkers, A. Butz, O. Hasekamp, S. Biraud, and E. Dlugokencky. 2016. "A Large Increase in US Methane Emissions over the Past Decade Inferred from Satellite Data and Surface Observations." Geophysical Research Letters. http://onlinelibrary.wiley.com/doi/10.1002/2016GL067987/abstract.

UNEP Risoe. 2014. "CDM/JI Pipeline Databases." United Nations Environment Programme. http://www.cdmpipeline.org/.

van Benthem, Arthur, and Suzi Kerr. 2013. "Scale and Transfers in International Emissions Offset Programs." Journal of Public Economics 107 (November): 31-46. doi:10.1016/j.jpubeco.2013.08.004.

Warnecke, C. 2014. "Can CDM Monitoring Requirements Be Reduced While Maintaining Environmental Integrity?" Climate Policy, 1-24. doi:10.1080/14693062.2014.875285.

Wartmann, S., H. Groenenberg, and S. Brockett. 2009. "Monitoring and Reporting of GHG Emissions from CCS Operations under the EU ETS." Energy Procedia 1 (1): 4459-66.

Weitzman, M. 1974. "Prices vs. Quantities." The Review of Economic Studies, 477-91.

\section{Appendices}

\section{Appendix 1 - Details on the empirical values used in simulations}

For our simulations, we use the data publicly available for energy efficiency and landfill gas flaring (LFG) CDM projects, assuming that they represent a typical investment to reduce GHG emissions. The parameter sets are given in Table 1. The method to derive these parameters from existing databases is described below.

Table 1 - Parameter sets for numerical simulations 


\begin{tabular}{l|lrr} 
Parameter & Unit & Energy efficiency projects & Landfill gas flaring projects \\
\hline b & $€ /$ tCO2e & 150 & 0 \\
p & $€ / \mathrm{tCO} 2 \mathrm{e}$ & 30 & 30 \\
c & $€ /(\mathrm{tCO} 2 \mathrm{e})^{2}$ & $9.93 \mathrm{E}-06$ & $5.46 \mathrm{E}-05$ \\
m & $€$ & $3.00 \mathrm{E}+02$ & $3.00 \mathrm{E}+02$ \\
c0 & $€$ & $1.79 \mathrm{E}+06$ & $1.97 \mathrm{E}+06$
\end{tabular}

Carbon price $\boldsymbol{p}$ is assumed to be equal to EUR 30 pert $\mathrm{CO}_{2} \mathrm{e}$, roughly the price of USD 40 at which the pricecontainment reserve of the Californian ETS is released (EDF 2013) and slightly above the average pre-crisis carbon prices in the EU ETS.

Non-carbon benefits $\boldsymbol{b}$ in energy efficiency projects are assumed to be equal to EUR 150 per $t \mathrm{CO}_{2} \mathrm{e}$, the potential cost-savings from reduced electricity consumption at the average grid carbon intensity of $0.5 \mathrm{t}$ $\mathrm{CO}_{2} \mathrm{e}$ per MWh - the average level in the OECD countries in 2010 (Brander et al. 2011) - and the electricity price of EUR 75 per MWh - the average electricity price for industry in the OECD in 2009 (IEA 2012). For landfill gas flaring projects $\boldsymbol{b}=\mathbf{0}$ as there are no additional revenues other than carbon.

Variable monitoring costs parameter $\boldsymbol{m}$ is obtained by fitting the function "costs $=\mathrm{m} /$ (relative error)^2" on the estimates provided by Powell (1999) for a forestry project. We generalize it to energy efficiency and LFG projects based on two comforting points: the rationale of Powell (1999) - decreasing uncertainty through increased sample size - is consistent with our modelling approach and the resulting variable monitoring costs for a typical uncertainty of $10 \%$ is EUR 30,000 , that is half the average total MRV costs (including fixed costs) for these project types, as estimated for the CDM (Shishlov 2015).

Fixed and variable abatement costs parameters $\boldsymbol{c}_{\mathbf{0}}$ and $\mathbf{c}$ are obtained from investments costs in CDM projects of type "Energy efficiency own generation" and "Landfill gas flaring", as estimated by UNEP Risoe (2014). For each project in the database, an estimate of investment costs per $\mathrm{tCO}_{2} \mathrm{e}$ abated excluding variable monitoring costs is obtained by subtracting EUR 30,000 to total investment costs (see above). The resulting cumulative marginal abatement cost curve (MACC), obtained from many different projects -245 for energy efficiency and 52 for LFG - is scaled down to a single project to be consistent with our modelling approach. To this end, we assume that the marginal abatement costs of our single project - the size of which is the average size of existing projects of the same type ${ }^{2}$ - are assumed to be proportional to those

\footnotetext{
2 That is 784 kt $\mathrm{CO}_{2}$ e over 7 years for energy efficiency projects and 682 kt $\mathrm{CO}_{2} \mathrm{e}$ over 7 years for LFG projects. For LFG projects, the cumulative MACC is truncated: projects with abatement costs excluding variable monitoring costs
} 
of the cumulative MACC. $c_{0}$ and $c$ are then obtained by fitting the relevant equation (cost $=c_{0}+c^{*} q^{\wedge} 2$ ) to this "scaled-down" MACC.

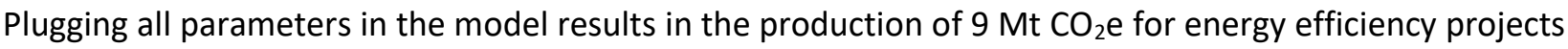
and $0.27 \mathrm{Mt} \mathrm{CO}_{2} \mathrm{e}$ for landfill gas flaring projects under no information asymmetry, both of which are within the range of existing projects in the database (0.08-20 Mt $\mathrm{CO}_{2} \mathrm{e}$ and 0.07-6 $\mathrm{Mt} \mathrm{CO}_{2} \mathrm{e}$ respectively).

\section{Appendix 2 - Comparison of outcomes under different scenarios (analytical results)}

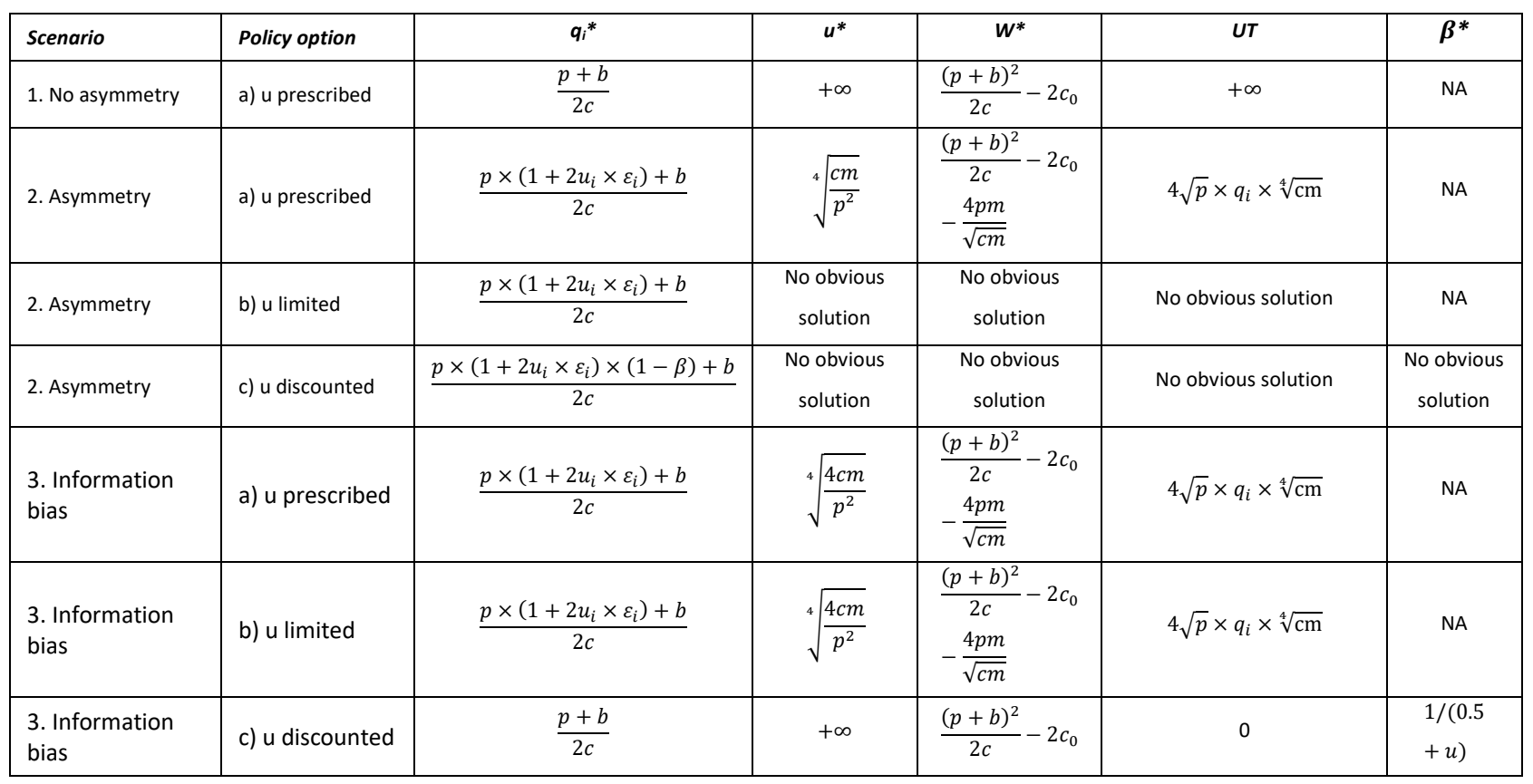

\section{Appendix 3 - Comparison of outcomes under different scenarios (numerical results for EE projects)}

\begin{tabular}{|c|c|c|c|c|c|c|c|c|c|c|c|c|c|c|}
\hline & $\begin{array}{l}\text { Q1*(Kt } \\
\text { CO2e) }\end{array}$ & $\begin{array}{l}\mathrm{Q} 2 *(\mathrm{Kt} \\
\mathrm{CO} 2 \mathrm{e})\end{array}$ & $\begin{array}{l}\mathrm{Q}^{*}(\mathrm{Kt} \\
\mathrm{CO} 2 \mathrm{e})\end{array}$ & $\begin{array}{l}\mathrm{W}^{*} \\
(\mathrm{M} €)\end{array}$ & $\begin{array}{l}\text { W loss } \\
(\%)\end{array}$ & $\begin{array}{l}\mathrm{P} 2^{*} \\
\text { (M€) }\end{array}$ & $\begin{array}{l}\text { W2* } \\
(\mathrm{M} €)\end{array}$ & $\begin{array}{l}\text { UT1 } \\
\text { (M€) }\end{array}$ & $\begin{array}{l}\text { UT2 } \\
\text { (M€) }\end{array}$ & $\begin{array}{l}\text { UTA } \\
\text { (M€) }\end{array}$ & u1* (\%) & $\mathrm{u} 2 *(\%)$ & $\mathrm{t} *(\%)$ & beta* \\
\hline Case 1a & 9.06 & 9.06 & 18.13 & 1,628 & $0.00 \%$ & 542.02 & 813.92 & 271.90 & -271.90 & 0.00 & $50.00 \%$ & $50.00 \%$ & $50.00 \%$ & NA \\
\hline Case $2 \mathrm{a}$ & 9.19 & 8.93 & 18.13 & 1,627 & $-0.04 \%$ & 790.72 & 813.59 & 23.53 & -22.87 & 0.66 & $4.27 \%$ & $4.27 \%$ & $4.27 \%$ & NA \\
\hline Case $2 b$ & 9.19 & 9.03 & 18.22 & 1,625 & $-0.19 \%$ & 805.50 & 811.11 & 23.52 & -5.61 & 17.92 & $4.27 \%$ & $1.03 \%$ & $4.27 \%$ & NA \\
\hline Case $2 c$ & 9.18 & 9.02 & 18.20 & 1,624 & $-0.24 \%$ & 802.54 & 810.13 & 78.02 & -4.78 & 73.24 & $17.91 \%$ & $0.89 \%$ & NA & 1.17 \\
\hline Case 3a & 9.19 & 9.19 & 18.38 & 1,627 & $-0.04 \%$ & 837.12 & 813.59 & 23.53 & 23.53 & 47.05 & $4.27 \%$ & $4.27 \%$ & $4.27 \%$ & NA \\
\hline Case $3 b$ & 9.19 & 9.19 & 18.38 & 1,627 & $-0.04 \%$ & 837.12 & 813.59 & 23.53 & 23.53 & 47.05 & $4.27 \%$ & $4.27 \%$ & $4.27 \%$ & NA \\
\hline Case $3 c$ & 9.06 & 9.06 & 18.13 & 1,628 & $0.00 \%$ & 813.92 & 813.92 & 0.00 & 0.00 & 0.00 & $50.00 \%$ & $50.00 \%$ & NA & $1 /(u+0.5)$ \\
\hline
\end{tabular}

higher than $4.05 € / \mathrm{tCO}_{2} \mathrm{e}$ are excluded. Over this threshold, abatement cost rises steeply, thus strongly violating our assumption of linear increase. The truncated MACC covers 52 out of 77 projects in the database. 


\section{Appendix 4 - Comparison of outcomes under different scenarios (numerical results for LFG projects)}

\begin{tabular}{|c|c|c|c|c|c|c|c|c|c|c|c|c|c|c|}
\hline & $\begin{array}{l}\mathrm{Q} 1 *(\mathrm{Kt} \\
\mathrm{CO} 2 \mathrm{e})\end{array}$ & $\begin{array}{l}\mathrm{Q} 2 *(\mathrm{Kt} \\
\mathrm{CO} 2 \mathrm{e})\end{array}$ & $\begin{array}{l}\mathrm{Q}^{*}(\mathrm{Kt} \\
\mathrm{CO} 2 \mathrm{e})\end{array}$ & $\begin{array}{l}\mathrm{W}^{*} \\
(\mathrm{M} €)\end{array}$ & $\begin{array}{l}\text { W loss } \\
(\%)\end{array}$ & $\begin{array}{l}\mathrm{P} 2^{*} \\
(\mathrm{M} €)\end{array}$ & $\begin{array}{l}\text { W2* } \\
(\mathrm{M} €)\end{array}$ & $\begin{array}{l}\text { UT1 } \\
\text { (M€) }\end{array}$ & $\begin{array}{l}\text { UT2 } \\
\text { (M€) }\end{array}$ & $\begin{array}{l}\text { UTA } \\
\text { (M€) }\end{array}$ & u1* (\%) & u2* (\%) & $\mathrm{t}^{*}(\%)$ & beta* \\
\hline Case 1a & 0.27 & 0.27 & 0.55 & 4.30 & $0.00 \%$ & -6.09 & 2.15 & 8.24 & -8.24 & 0.00 & $50.00 \%$ & $50.00 \%$ & $50.00 \%$ & NA \\
\hline Case 2a & 0.31 & 0.24 & 0.55 & 4.02 & $-6.49 \%$ & 1.07 & 2.01 & 1.22 & -0.94 & 0.28 & $6.53 \%$ & $6.53 \%$ & $6.53 \%$ & NA \\
\hline Case $2 b$ & 0.31 & 0.26 & 0.57 & 3.88 & $-9.72 \%$ & 1.35 & 1.87 & 1.22 & -0.52 & 0.70 & $6.53 \%$ & $3.39 \%$ & $6.53 \%$ & NA \\
\hline Case 2c & 0.29 & 0.25 & 0.54 & 3.90 & $-9.34 \%$ & 1.08 & 1.78 & 2.35 & -0.43 & 1.92 & $16.77 \%$ & $2.97 \%$ & NA & 1.21 \\
\hline Case $3 a$ & 0.31 & 0.31 & 0.62 & 4.02 & $-0.04 \%$ & 3.23 & 2.01 & 1.22 & 1.22 & 2.43 & $6.53 \%$ & $6.53 \%$ & $6.53 \%$ & NA \\
\hline Case 3b & 0.31 & 0.31 & 0.62 & 4.02 & $-0.04 \%$ & 3.23 & 2.01 & 1.22 & 1.22 & 2.43 & $6.53 \%$ & $6.53 \%$ & $6.53 \%$ & NA \\
\hline Case $3 c$ & 0.27 & 0.27 & 0.55 & 4.30 & $0.00 \%$ & 2.15 & 2.15 & 0.00 & 0.00 & 0.00 & $50.00 \%$ & $50.00 \%$ & NA & $1 /(u+0.5)$ \\
\hline
\end{tabular}

Notes: $\mathrm{Q}^{*}, \mathrm{Q}^{*}$ and $\mathrm{Q}^{*}$ are the amount of emissions reductions in $\mathrm{Mt} \mathrm{CO}_{2} \mathrm{e}$ from Agent 1, Agent 2 and both agents respectively. W* is the total welfare in $\mathrm{M} € . \mathrm{W}$ loss is the welfare loss compared to case $1 \mathrm{a}$ (no asymmetry). P2* is the profit of Agent 2 , and W2* the welfare generated by his participation. UT1, UT2 and UTA are the undue wealth transfers from society to Agent 1, Agent 2 or both agents respectively (undue wealth transfers corresponds to the payments of non-existing emissions reductions or to the unpaid emissions reductions. The latter case happens for Agent 2 whose emissions reductions are underestimated. This is why UT2 is often negative). u1* and u2* are the optimal (or prescribed in policy a) monitoring errors for Agent 1 and Agent 2 respectively. $t^{*}$ is the optimal (or prescribed in policy a) maximum tolerated error. Beta is the optimal discount rate.

\section{Appendix 5 - Derivations for case 1a}

$$
\begin{gathered}
E\left(\pi_{\mathrm{i}}\right)=p \times q_{\mathrm{i}}+b \times q_{\mathrm{i}}-c_{0}-c \times q_{\mathrm{i}}{ }^{2}-\frac{m}{u^{2}} \\
\frac{\partial \pi}{\partial q}=p+b-2 c q \\
q_{1}{ }^{*}=q_{2}{ }^{*}=\frac{p+b}{2 c} \\
q^{*}=q_{1}{ }^{*}+q_{2}{ }^{*}=\frac{p+b}{c} \\
W=2\left(q_{1}{ }^{*} \times(p+b)-c_{0}-c \times q_{1}{ }^{* 2}-\frac{m}{u^{2}}\right) \\
\frac{\partial W}{\partial u}=\frac{4 m}{u^{3}}>0 \\
u^{*}=+\infty \\
W^{*}=\lim _{u \rightarrow \infty} 2\left(q_{1}{ }^{*} \times(p+b)-c_{0}-c \times q_{1}{ }^{* 2}-\frac{m}{u^{2}}\right)
\end{gathered}
$$


Note that our assumption that $\boldsymbol{\varepsilon}$ and $\boldsymbol{q}$ are independent is crucial here. Although we think it is generally warranted as $\varepsilon$ is the relative standard error, it may not always be the case.

\section{Appendix 6 - Derivations for case 2a}

Profit of agent i:

$$
\begin{aligned}
& \pi_{\mathrm{i}}=p \times q_{r \mathrm{i}}+b \times q_{\mathrm{i}}-c_{0}-c \times q_{\mathrm{i}}^{2}-\frac{m}{u^{2}}=p \times q_{\mathrm{i}} \times\left(1+2 u \varepsilon_{i}\right)+b \times q_{1}-c_{0}-c \times q_{\mathrm{i}}^{2}-\frac{m}{u^{2}} \\
& \frac{\partial \pi_{\mathrm{i}}}{\partial q_{\mathrm{i}}}=p \times\left(1+2 u \varepsilon_{i}\right)+b-2 c q_{\mathrm{i}} \\
& q_{\mathrm{i}}^{*}=\frac{p \times\left(1+2 u \varepsilon_{i}\right)+b}{2 c}
\end{aligned}
$$

Welfare:

$$
\begin{gathered}
W=q_{1}{ }^{*} \times(p+b)-c_{0}-c \times q_{1}{ }^{* 2}-\frac{m}{u^{2}}+q_{2}{ }^{*} \times(p+b)-c_{0}-c \times q_{2}{ }^{2}-\frac{m}{u^{2}}= \\
(p+b)\left(\left(\frac{p(1+2 u)+b}{2 c}\right)+\left(\frac{p(1-2 u)+b}{2 c}\right)\right)-c\left(\left(\frac{p(1+2 u)+b}{2 c}\right)^{2}+\left(\frac{p(1-2 u)+b}{2 c}\right)^{2}\right)-2 c_{0}-\frac{2 m}{u^{2}} \\
=\frac{(p+b)^{2}}{2 c}-\frac{2 p^{2} u^{2}}{c}-2 c_{0}-\frac{2 m}{u^{2}} \\
\frac{\partial W}{\partial u}=\frac{4\left(c m-p^{2} u^{4}\right)}{c u^{3}} \\
W^{*}=\frac{(p+b)^{2}}{2 c}-2 c_{0}-\frac{2 p^{2} \sqrt{\frac{c m}{p^{2}}}}{c}-\frac{2 m}{\sqrt{\frac{c m}{p^{2}}}}=\frac{(p+b)^{2}}{2 c}-2 c_{0}-\frac{4 p m}{\sqrt{c m}}
\end{gathered}
$$

Modelling this situation with a continuum of agents whose $\boldsymbol{\varepsilon}_{\boldsymbol{i}}$ are equally distributed over [-1;1] leads to a similar result on welfare:

$$
\begin{gathered}
W=\int_{-1}^{1} q^{*} \times(p+b)-c \times q^{* 2}-c_{0}-\frac{m}{u^{2}} d \varepsilon \\
=\int_{-1}^{1} \frac{(p+b)}{2 c}(p+b)+\frac{\varepsilon u p}{c}(p+b)-c\left[\frac{(p+b)}{2 c}+\frac{\varepsilon u p}{c}\right]^{2} d \varepsilon-2\left(c_{0}-\frac{m}{u^{2}}\right)
\end{gathered}
$$




$$
\begin{gathered}
\int_{-1}^{1} \frac{\varepsilon u p}{c}(p+b)-c\left[\frac{(p+b)^{2}}{4 c^{2}}+\frac{\varepsilon^{2} u^{2} p^{2}}{c^{2}}+\frac{2 \varepsilon u p}{2 c^{2}}(p+b)\right] d \varepsilon+2\left(\frac{(p+b)^{2}}{2 c}-c_{0}-\frac{m}{u^{2}}\right) \\
=-\frac{1}{4 c} \int_{-1}^{1} 4 \varepsilon^{2} u^{2} p^{2}+(p+b)^{2} d \varepsilon+2\left(\frac{(p+b)^{2}}{2 c}-c_{0}-\frac{m}{u^{2}}\right) \\
=-\frac{1}{4 c}\left(\frac{8 u^{2} p^{2}}{3}+2(p+b)^{2}\right)+2\left(\frac{(p+b)^{2}}{2 c}-c_{0}-\frac{m}{u^{2}}\right) \\
=\frac{(p+b)^{2}}{2 c}-\frac{2 u^{2} p^{2}}{3 c}-2 c_{0}-\frac{2 m}{u^{2}} \\
\frac{\partial W}{\partial u}=\frac{4\left(c m-p^{2} u^{4}\right)}{3 c u^{3}}
\end{gathered}
$$

First order condition:

$$
u^{*}=\sqrt[4]{\frac{3 c m}{p^{2}}}
$$

The solution is therefore very similar to the representation with two opposite agents:

$$
u_{\text {continuum }}^{*}=u^{*}{ }_{2 \text { agents }} \sqrt[4]{3}
$$

Quite intuitively, a uniform distribution of agents over [-1;1] decreases the inefficiency generated by monitoring uncertainty compared to a distribution where $\boldsymbol{\varepsilon}_{\boldsymbol{i}}$ clusters on $\{-1 ; 1\}$ since the effect of adverse selection is lower for values of $\boldsymbol{\varepsilon}_{\boldsymbol{i}}$ closer to zero. As a result, the cost of monitoring weights relatively more on welfare and $u^{*}$ is $30 \%$ higher.

\section{Appendix 7 - Derivations for case $2 b$}

For the case of underestimation of emissions reductions:

$$
\begin{gathered}
\frac{\boldsymbol{\partial} \boldsymbol{\pi}}{\boldsymbol{\partial \boldsymbol { u } _ { 2 \boldsymbol { b } , \mathbf { 2 } }}}=-\mathbf{2} \boldsymbol{p} \boldsymbol{q}_{2 \boldsymbol{b}, \mathbf{2}}+\frac{\mathbf{2 m}}{\boldsymbol{u}_{2 \boldsymbol{b}, \mathbf{2}}{ }^{3}} \\
u_{2 b, 2}{ }^{*}=\sqrt[3]{\frac{m}{p q_{2 b, 2}}}
\end{gathered}
$$

\section{Appendix 8 - Derivations for case 2c}

$$
\pi_{i}=p \times q_{i} \times\left(1+2 \varepsilon_{i} u_{i}\right) \times\left(1-\beta u_{i}\right)+b \times q-c_{0}-c \times q^{2}-\frac{m}{u_{i}^{2}}
$$




$$
\begin{gathered}
\frac{\partial \pi_{i}}{\partial q}=p \times\left(1+2 \varepsilon_{i} u_{i}\right) \times\left(1-\beta u_{i}\right)+b-2 c q \\
q_{i}^{*}=\frac{p \times\left(1+2 \varepsilon_{i} u_{i}\right) \times\left(1-\beta u_{i}\right)+b}{2 c}
\end{gathered}
$$

\section{Appendix 9 - Derivations for cases $3 a$ and $3 b$}

For both agents:

$$
\begin{gathered}
\pi_{1}=\pi_{2}=p \times q \times(1+2 u)+b \times q-c_{0}-c \times q^{2}-\frac{m}{u^{2}} \\
\frac{\boldsymbol{\partial} \boldsymbol{\pi}}{\boldsymbol{\partial \boldsymbol { q }}}=\boldsymbol{p} \times(\mathbf{1}+\mathbf{2 u})+\boldsymbol{b}-\mathbf{2 c \boldsymbol { q }} \\
q^{*}=\frac{p \times(1+2 u)+b}{2 c}
\end{gathered}
$$

Welfare:

$$
\begin{gathered}
W=2\left[(p+b)\left(\frac{p(1+2 u)+b}{2 c}\right)-c\left(\frac{p(1+2 u)+b}{2 c}\right)^{2}-c_{0}-\frac{m}{u^{2}}\right]==\frac{(p+b)^{2}}{2 c}-\frac{2 p^{2} u^{2}}{c}-2 c_{0}-\frac{2 m}{u^{2}} \\
\frac{\partial W}{\partial u}=\frac{4\left(c m-p^{2} u^{4}\right)}{c u^{3}} \\
u^{*}=\sqrt[4]{\frac{c m}{p^{2}}} \\
W^{*}=\frac{(p+b)^{2}}{2 c}-2 c_{0}-\frac{2 p^{2} \sqrt{\frac{c m}{p^{2}}}}{c}-\frac{2 m}{\sqrt{\frac{c m}{p^{2}}}}=\frac{(p+b)^{2}}{2 c}-2 c_{0}-\frac{4 p m}{\sqrt{c m}}
\end{gathered}
$$

\section{Appendix 10 - Derivations for cases 3c}

For both agents:

$$
\begin{gathered}
\pi=p \times q \times(1+2 \varepsilon u) \times(1-\beta u)+b \times q-c_{0}-c \times q^{2}-\frac{m}{u^{2}} \\
\frac{\partial \pi}{\partial q}=p \times(1+2 u) \times(1-\beta u)+b-2 c q \\
q^{*}=\frac{p \times(1+2 u) \times(1-\beta u)+b}{2 c}
\end{gathered}
$$

